
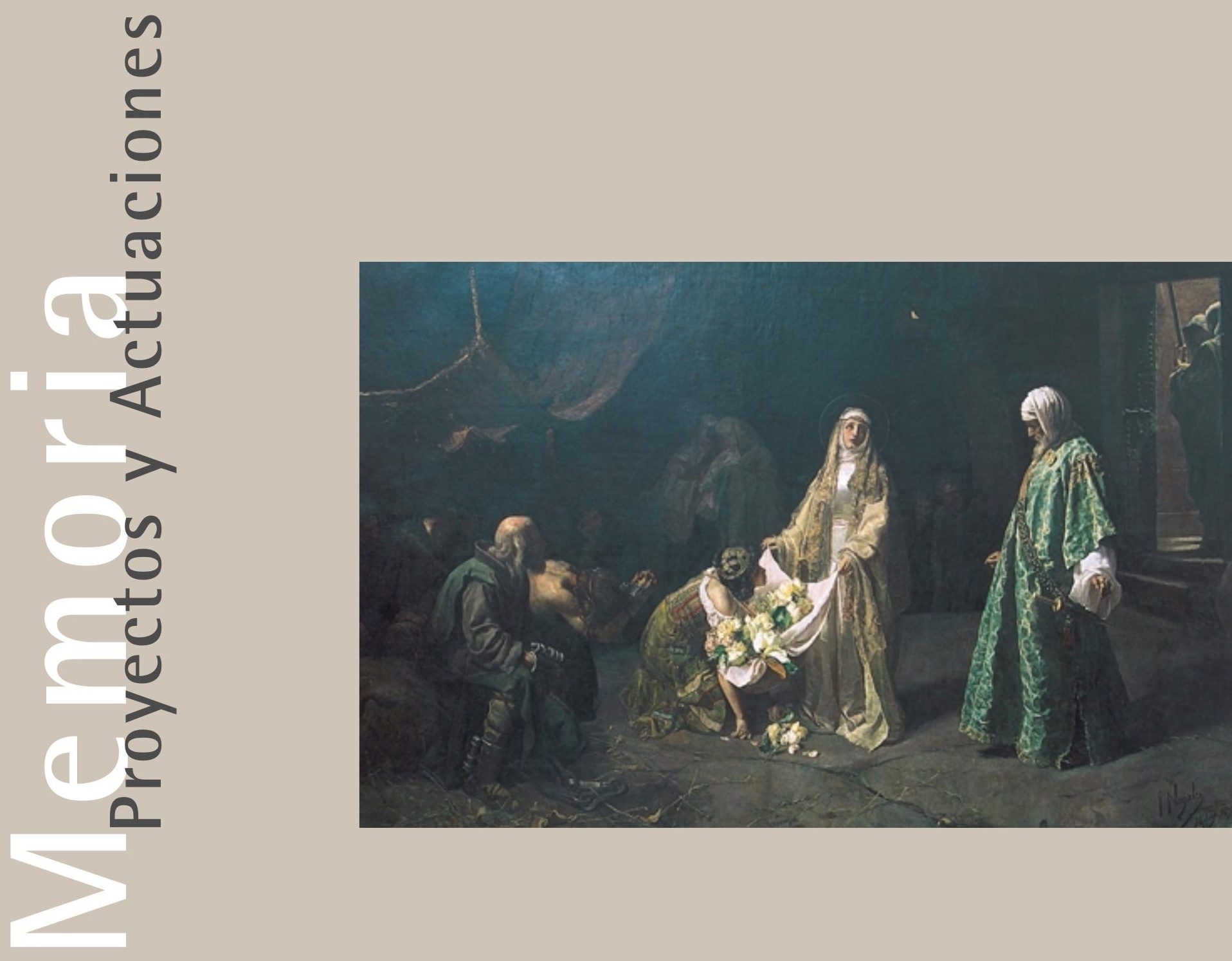

\title{
Intervención en el óleo sobre lienzo "El milagro de Santa Casilda" de José Nogales Sevilla (1892)
}

Ma del Mar González González Restauradora

Centro de Intervención. IAPH

Lorenzo Pérez del Campo

Jefe del Centro de Intervención. IAPH 


\section{La pintura malagueña en el s. XIX}

Como ha señalado la profesora Teresa Sauret, hasta mitad del siglo XIX Málaga dependió, pictóricamente hablando, de Cádiz y Sevilla, por la sencilla razón de que en aquella ciudad no se producía prácticamente pintura. Ajustando aún más, la citada experta apunta que Cádiz tuvo un papel más significativo sobre Málaga que Sevilla !.

Este panorama cambió a partir de 1849 y entre esta fecha y 1870 la madrileña Escuela de Bellas Artes de San Fernando marcó nuevas directrices conceptuales y técnicas en la pintura malagueña. Como correa de transmisión actuó la recién creada Academia de Bellas Artes de San Telmo, impulsando ésta por medio de la Escuela de Bellas Artes, el desarrollo de una estética basada en la supremacía del contenido y del dibujo sobre la forma y el color.

Un segundo giro se produjo a partir de 1870. La presencia en Málaga del núcleo valenciano formado por Bernardo Ferrándiz, Antonio Muñoz Degrain y Antonio Galbién trajo a la ciudad nuevos modos estéticos que recogieron tanto el modelo específico valenciano como otro más amplio relacionado con las apuestas conceptuales que, en el orden plástico, se desarrollaban en ese momento en Madrid y sobre todo, en París y Roma. Este nuevo lenguaje (fortunismo) cimentó gran parte de su efectismo en el color: rico, brillante y armónicamente dispuesto y en un generoso uso de la luz asociada al color, que resalta y potencia los valores pictóricos de las obras, informando sobre los acontecimientos que se desarrollan en el cuadro. No menos importante recurso al "efecto volumen", relacionado directamente con el tema representado. En resumen, una pintura de más impacto cromático y lumínico basada en una temática más "agradable" que la anteriormente establecida. Esta estética fue muy del gusto de la burguesía local, que canalizó numerosos encargos que terminaron por consolidar la opción.

Esta sucesión de hechos permite comprender adecuadamente el análisis artístico del siglo XIX malagueño en lo que a pintura se refiere. Análisis complicado por cuanto, como se ha visto, en el período asistimos a una acumulación vertiginosa de ideas que, como en tantas ocasiones, desembocaron en un eclecticismo dominante. En este marco general hay que situar la figura de José Nogales Sevilla.

\section{José Nogales}

Nogales nació en Málaga en 1860 recibiendo formación artística en la Escuela de Bellas Artes entre 1878 y 1882. En este centro docente asistió a las clases de Ferrándiz. Más tarde completó sus estudios en el taller de Muñoz Degrain. Ejemplo de artista adecuado a la estética oficial imperante, Nogales se muestra, básicamente como un ecléctico pintor poseedor de una sólida y muy trabajada técnica. Siguió literalmente las enseñanzas de Degrain afrontando el natural desde una posición de sincera objetividad especialmente reseñable en los retratos, que aborda desde un concepto altamente realista.

En 1893 ingresó por oposición en el claustro de profesores de la Escuela de Bellas Artes, impartiendo la docencia en la asignatura "Dibujo de figura". En 190। fue designado Académico de San Fernando y vocal de la Comisión Provincial de Monumentos Artísticos e Históricos de Málaga. Al año siguiente fue nombrado Director de la Escuela, cargo al que renunció poco después a causa de su delicado estado de salud. Hasta su jubilación en 1931 simultaneó sus obligaciones docentes con el ejercicio privado de la profesión y la participación en exposiciones y certámenes. Nogales falleció en Málaga en noviembre de 1939. (Morales, 1973 y Sauret, 1987).

José Nogales apenas salió de Málaga sino para realizar, ya en edad madura, un par de viajes de trabajo a Granada, ciudad en la que pintó "Cipreses del Generalife" ( 1896, Museo de Málaga). A pesar de esta circunstancia, aparentemente negativa, José Nogales supo incorporar a su obra elementos que denuncian cierta preocupación por determinados problemas conceptuales vinculados a las inquietudes artísticas y poéticas que preocupaban a buena parte de los intelectuales europeos de finales del siglo XIX. En éste interés se fundamenta buena parte del reconocimiento que de Nogales hace la historiografía artística especializada que ve en él a uno de los pintores malagueños más completos del siglo XIX (Sauret, 1987).

\section{El “Milagro...”: historia material}

La crítica especializada ha venido considerando "El Milagro de Santa Casilda" como la obra más internacional de Nogales y en la que se cimenta buena parte de la fama del artista. El cuadro fue presentado, con gran éxito crítico, a la Exposición Internacional de Bellas Artes de 1892 siendo galardonado con el premio de primera clase al mérito en la sección de Pintura, compartido junto al "Flevit super illam" de Simonet, hoy en el Museo de Málaga. En 1931 "El Milagro..." formó parte de la Antológica organizada en Málaga con ocasión de la jubilación académica del artista. El cuadro fue adquirido por un banquero quién lo donó al Convento de las Salesas Reales de Oviedo en devoción a la santa castellana y recuerdo a su hija llamada Casilda, monja profesa en el citado cenobio. En julio de 1972 la Comunidad de Salesas enajenó el lienzo que fue adquirido por el Anticuario Esperanza de la capital de Asturias.

En este establecimiento comercial permanecía en 1994 cuando la Consejería de Cultura de la Junta de Andalucía inició gestiones para su adquisición con destino al Museo de Málaga. La compra se materializó en el verano de 1996.

El estado de conservación de la obra obligaba a una minuciosa investigación e intervención antes de su exposición pública en el citado Museo. Con este fin, el 
cuadro fue depositado el 25 de setiembre de 1996 en el Instituto Andaluz del Patrimonio Histórico. En la capital de Asturias, y antes del traslado, doña Clara González-Fanjul, del Museo de Oviedo, realizó siguiendo las indicaciones del I.A.P.H., una intervención de urgencia que consistió, básicamente, en la protección de la película pictórica con objeto de facilitar el enrolle del lienzo en un rulo (el cuadro en Oviedo no tenía bastidor) en el que viajó a Sevilla a bordo de un transporte especializado ${ }^{2}$.

Concluida la intervención en el I.A.P.H., el cuadro fue trasladado a Málaga en setiembre de 1999, e incorporado a los fondos pictóricos del Museo, siendo depositado temporalmente en la Sala de Exposiciones del Archivo Histórico Provincial. Según lo establecido en el art. 60 de la Ley 16/85 de 25 de junio, del Patrimonio Histórico Español, el cuadro está sometido al régimen de protección que la citada Ley define para los Bienes de Interés Cultural.

\section{EI “Milagro...”: análisis de contenido}

El "Milagro de Santa Casilda" es un cuadro ecléctico en lo formal y codificado en lo conceptual. Narra cierto episodio en la vida de la princesa Casilda de Toledo (c. I 050-c. I l 07), de gran encanto hagiográfico por su sencillez y sabor de lo heroico. Hija del rey de Toledo Almacrín (Almamún) era princesa poseedora de un natural abundante en clemencia y ternura. Rodeada de todo tipo de comodidades y atenciones en la fastuosidad de la corte, no soporta la aflicción de los desafortunados que están en las mazmorras. Siente una especial piedad que los cautivos y los intenta consolar llevándoles viandas en el hondón de su falda. Un día cuando realizaba esta labor misericordiosa, fue sorprendida por el Rey que le preguntó por lo que transportaba, contestándoles ella que "rosas", apareciendo al extender su falda, estas flores a la vista de su padre y los intrigantes cortesanos.

Es cierto que se trata formalmente de una narración histórica basada en una leyenda medieval pero ésta ha sido concebida dentro de unas coordenadas realistas-simbólicas que Nogales adopta en la intención de ejemplificar una práctica del género religioso que quiere incluirse en la modernidad finisecular. Junto a ello existe en el "Milagro..." una importante asimilación realista en el hecho de que los personajes han sido objetivados al responder a modelos reales del entorno familiar y académico del pintor, pero esta objetivación queda diluida al presentarlos Nogales con lujosos ropajes cortesanos de aspecto historicista.

El esqueleto estructural del cuadro viene determinado por una importante relación entre las trayectorias y direcciones de los movimientos oculares (CasildaAlmamún) y las estructura perceptiva de la imagen final que resulta de la exploración. Existe un punto móvil que se desliza continuamente hacia abajo, alrededor del mandil de flores, en el que, como se ha dicho, se descarga todo el contenido simbólico de la historia (pan/flores=traición/caridad). En relación con

lo anterior, es evidente que el conocimiento intelectual ha ayudado a la formulación del concepto visual pero sólo en la medida en que ha sido traducido a atributos visuales de gran calidad plástica en los que es estimular los sentidos mediante la percepción de los minuciosos detalles de las flores de Nogales.

Junto con sus valores formales y narrativos, las flores son un auténtico manifiesto de la temática, de indudable validez, aunque ésta hemos de leerla en clave local y no como partícipe de discursos más simbolistas de otra escala. Hemos de recordar que Nogales era un
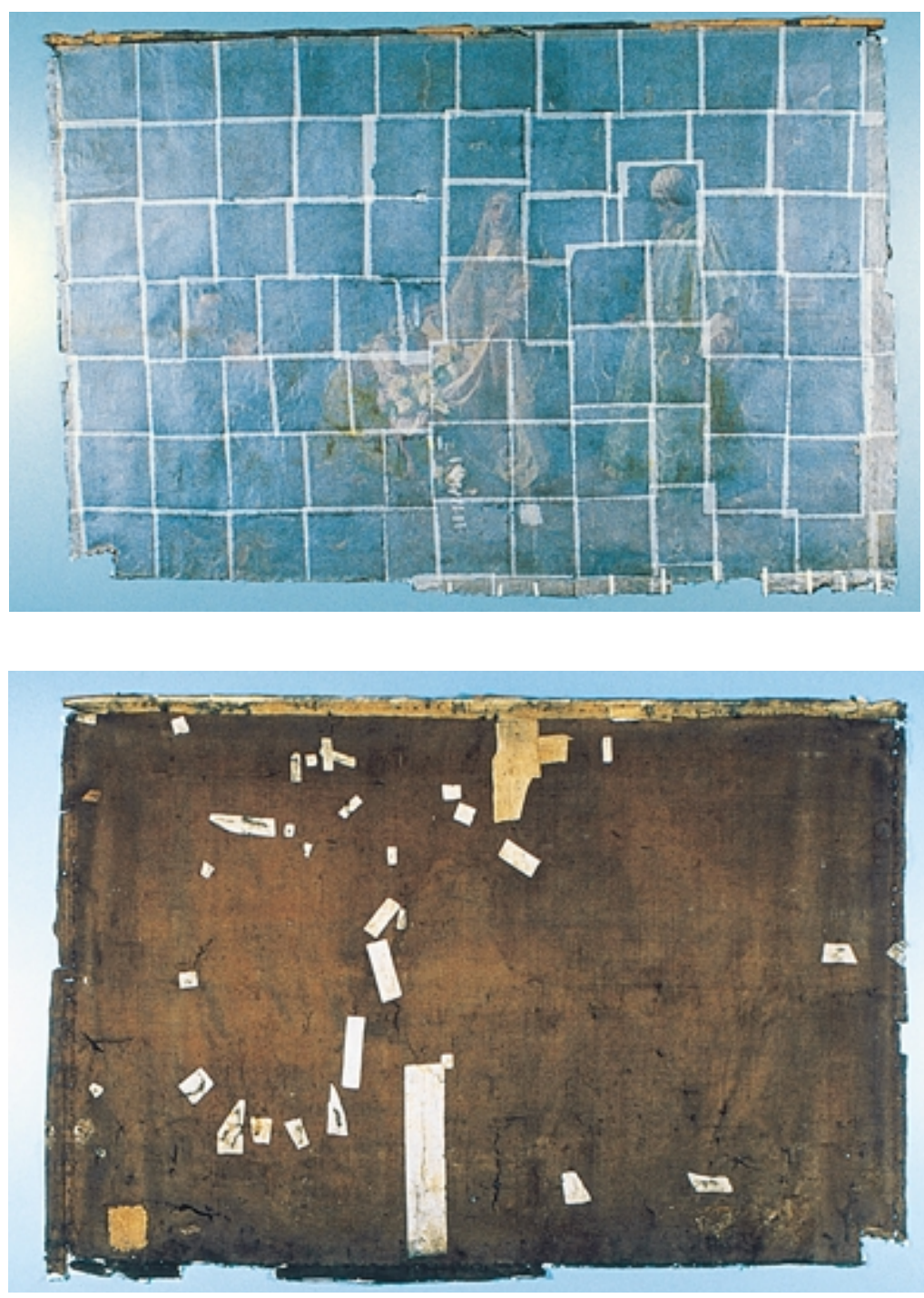

pintor especialista en temas vegetales y de género, altamente interesado en su interpretación a través de las nuevas poéticas. En las flores del "Milagro..." incorpora al cuadro estos componentes simbólicos y perceptivos de forma coherente hasta tal punto que su ubicación, además de orientar espacialmente la composición, introduce en la misma factores visuales tan importantes como la dirección y la velocidad de la acción.

La escena se desarrolla en un espacio negativo: una mazmorra. No obstante. Nogales ha sabido propor-
Toma general del cuadro a su llegada al IAPH, con la película pictórica protegida con papel japonés.

Toma general por el reverso antes de iniciar el proceso de restauración. 
$\frac{\pi}{0}$
0
$\Sigma$
$\Sigma$

cionar a este espacio cierta calidad de figura para ser perceptible por derecho propio. No es un espacio ambiguo. La percepción de la naturaleza del espacio es posible mediante un hábil uso de la puerta de acceso a la mazmorra que entraña, además, una curiosa paradoja visual, por cuanto que un área ciertamente pequeña ha sido elevada a la categoría de "figura" mediante el recurso del potente chorro de luz sobre el que se recorta una emboscada figura: el carcelero.

\section{EI proyecto de intervención del IAPH}

Como queda dicho, una vez adquirido el cuadro por la Junta de Andalucía en el año 1995, llega al Instituto Andaluz del Patrimonio Histórico el 25 de septiembre de 1996, y se deposita en el muelle de descarga de dicho centro hasta el 15 de noviembre, que es trasladado al taller de pintura.

En un primer Informe de Valoración realizado en 1994 3, consta, según testimonios orales de sus antiguos propietarios, que el lienzo fue rescatado de un desván, ya sin bastidor y doblado, hace unos veinte años. Cuando el cuadro fue adquirido por la Junta de Andalucía, se encontraba, desde hacía veintisiete años, colgado de una pared del almacén de antigüedades de Oviedo, sin bastidor, y sólo con un listón clavado al lienzo, en la parte superior, que servía para anclarlo al muro. Dadas las condiciones en que se encontraba la obra, en Septiembre de 1996 se llevan a cabo una se-

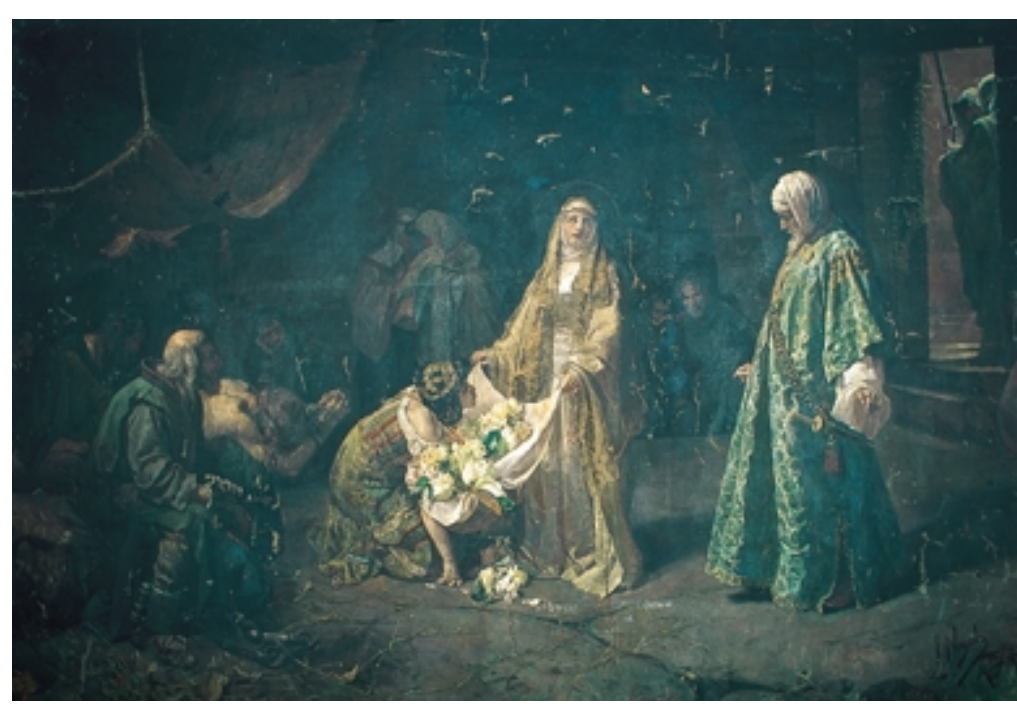

Toma general una vez reentelado el cuadro y eliminados los papeles de protección. rie de procesos previos para poder trasladar el cuadro, como la protección de la película pictórica y el desclavar el lienzo del muro ${ }^{4}$.

\section{Estudios preliminares}

En la inspección ocular que se llevó a cabo el día 3 de Diciembre de 1996, en el taller de fotografía, se recogieron los datos necesarios para determinar el estado de conservación del lienzo, y en consecuencia el pro- ceso de restauración a seguir. Estos estudios se completaron con los resultados de los análisis de las muestras recogidas ${ }^{5}$ y el reportaje fotográfico realizado ese mismo día.

Para una primera aproximación al estado de conservación de la obra, se tomaron muestras de tela de uno de los parches (colocados en intervenciones anteriores), de la tela original, de la pintura y de restos metálicos adheridos al lienzo por el reverso.

Sobre estas muestras, se efectuaron los siguientes análisis:

- La observación con lupa binocular.

- La observación al microscopio óptico con luz reflejada de la sección transversal (estratigrafía) estudio al microscopio electrónico de barrido y microanálisis (EDAX) de la sección transversal.

- Estudio de la sección transversal y longitudinal de las fibras, lavadas y decoloradas, al microscopio óptico.

- Ensayos microquímicos con diversos reactivos.

Los resultados obtenidos confirmaron que la fibra de la tela original era de lino, mientras que la naturaleza de los parches que cubrían la mayor parte del soporte pictórico, era de algodón. La preparación o imprimación del soporte, para recibir la capa de color, estaba compuesta por blanco de plomo 6 y blanco fijo, que confiere gran resistencia a la pintura. En la película de color, de las dos muestras analizadas, una de ellas presentaba una única capa de color oscuro, compuesta por blanco de plomo, sulfato de bario o blanco fijo y tierras, mientras que la segunda muestra de color analizada presentaba la siguiente secuencia estratigráfica: Capa de preparación, capa discontinua de color ocre, y las dos últimas capas formadas por tierras pardas, blanco de plomo, blanco fijo, y trazas de pigmento azul 7 .

Estos estudios previos se consideran una primera aproximación a la naturaleza de los materiales que componen la obra y a las características inherentes a ella, pues los estudios analíticos que se realizaron paralelamente a los tratamientos de conservación y restauración, determinaron con más claridad los resultados anteriores, e incluso, en algunos casos, modificaron los análisis iniciales.

\section{Estado de Conservación}

El pésimo estado de conservación, detectado en el minucioso examen visual llevado a cabo, era consecuencia directa de las condiciones en las que estuvo la obra durante muchos años, agravando la causa principal de estos daños la ausencia del bastidor, y las desafortunadas intervenciones anteriores sobre el soporte pictórico que pretendían conferirle estabilidad.

\section{SOPORTE PICTÓRICO}

El soporte pictórico estaba constituido por una sola pieza de tela de $317 \mathrm{~cm}$ de alto por $468 \mathrm{~cm}$ de lar- 
go. Las faltas y pérdidas del mismo estaban localizadas por todo el perímetro del lienzo y en el ángulo inferior derecho, al que corresponden dos piezas de tela original desprendidas y sobre las que se pudieron llevar a cabo los estudios con lupa binocular y detectar las pérdidas de soporte, los dobleces y superposiciones de la tela, los cosidos, los agujeros, los depósitos superficiales $y$, en resumen, el grado de deterioro del lienzo. También nos permitió determinar la construcción interna del tejido, técnicamente denominado "Louisine" 8, al basarse en el ligamento o cruce de dos hilos por urdimbre y uno por trama, siendo la densidad por $\mathrm{cm}^{2}$ de $10 / 1 /$ hilos por trama y $22 / 24$ hilos por urdimbre. La fibra era de lino, con torsión en $Z$ y números de cabos múltiples tanto por trama como por urdimbre, dispuesta ésta en sentido horizontal, al observar la orilla de la tela en algunas zonas del borde superior e inferior del lienzo.

\section{Alteraciones}

El soporte pictórico se encontraba bastante deteriorado, a pesar de las intervenciones anteriores que intentaban ocultar o solucionar daños de la obra, como agujeros, rotos o desgarros.

Los medios utilizados para tal fin eran de naturaleza diferente. En algunos casos, utilizaron parches, hasta un total de treintaiséis, de diferentes formas y tamaños. En la mayoría de ellos, la construcción interna del tejido era "Tafetán", con fibra de algodón, torsión en Z y número de cabos múltiples. En otros casos, emplearon papel de periódico, a modo de parche, como el localizado en el ángulo inferior izquierdo (hoja de periódico de "La Gaceta del Norte. Bilbao"). Igualmente, el borde superior del lienzo tenía adherido papel de embalar, por el reverso, y gasa, por el anverso, con el fin de reforzar la zona para clavar un listón de madera, al carecer el lienzo de bastidor, y poder colgarlo en el muro.

Al margen de la gran acumulación de polvo y suciedad, las alteraciones que presentaba el soporte pictórico afectaban tanto a la tela original como a las intervenciones anteriores realizadas sobre el mismo.

La mayoría de los rotos y desgarros generalizados por toda la superficie, estaban ocultos por los parches. Algunos de estos parches habían perdido su adherencia y ya no hacían la función de reforzar la tela original. Muchos de los agujeros que presentaba el soporte pictórico estaban localizados en el cuadrante inferior derecho, aunque también se detectaron marcas y agujeros con restos de óxido en la zona inferior y superior del lienzo, dispuestas en horizontal y a unos 23 y $33 \mathrm{~cm}$ del borde inferior y superior, respectivamente, y probablemente ocasionadas por el sistema de anclaje al muro mediante puntillas de hierro (tachuelas), además del listón de madera mencionado anteriormente.

Al haber permanecido durante mucho tiempo el lienzo en contacto directo con el muro o pared, sin la protección de un bastidor, las fuertes tensiones pro-

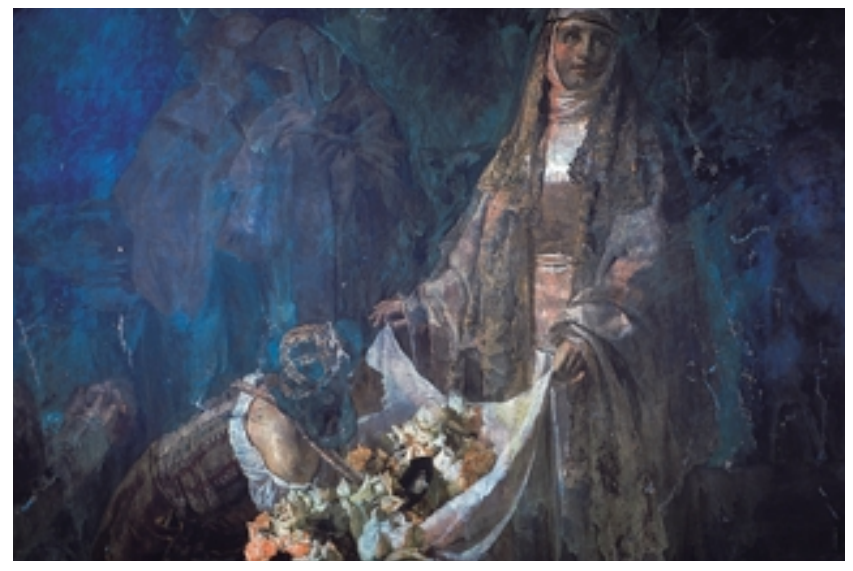

$\frac{\pi}{a}$

Detalle de la película pictórica con iluminación UV.

Gráfico del estado de conservación del soporte pictórico

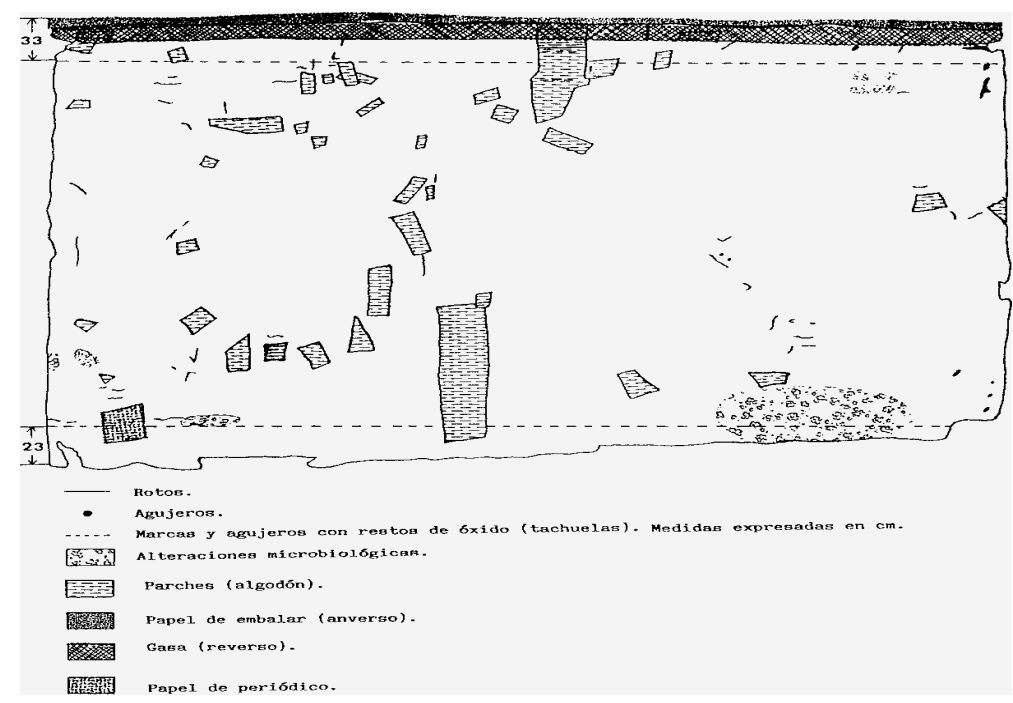

Gráfico de la construcción interna del tejido

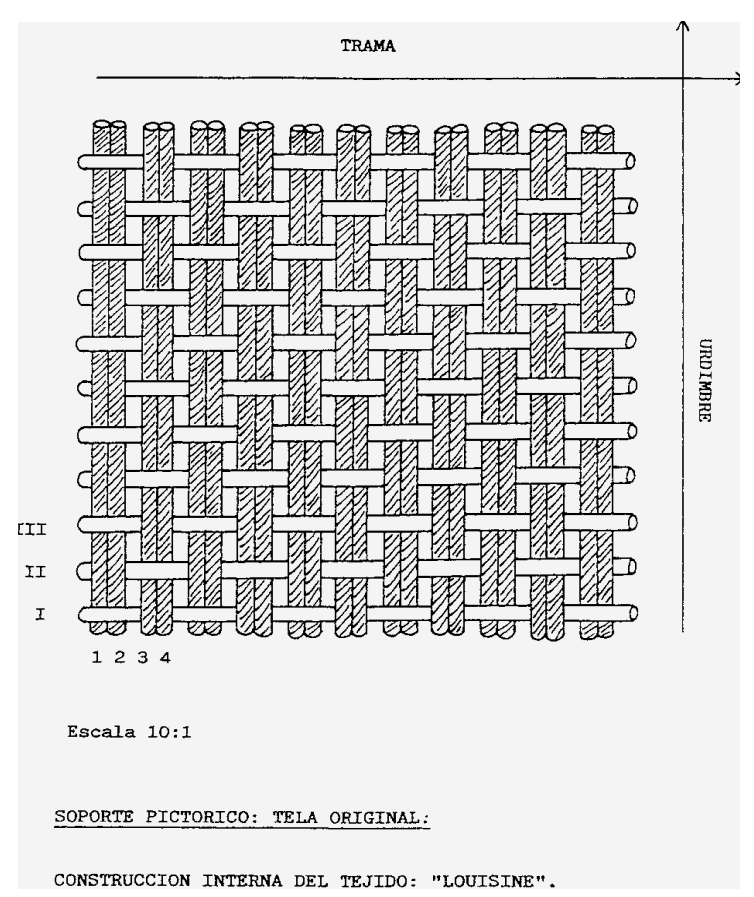


$\frac{\pi}{0}$
0
$\Sigma$
$\Sigma$

Gráfico de la disposición de los parches de seda natural y de la ubicación de las piezas de tela original $n^{\circ} I, 2,3$ y 4.
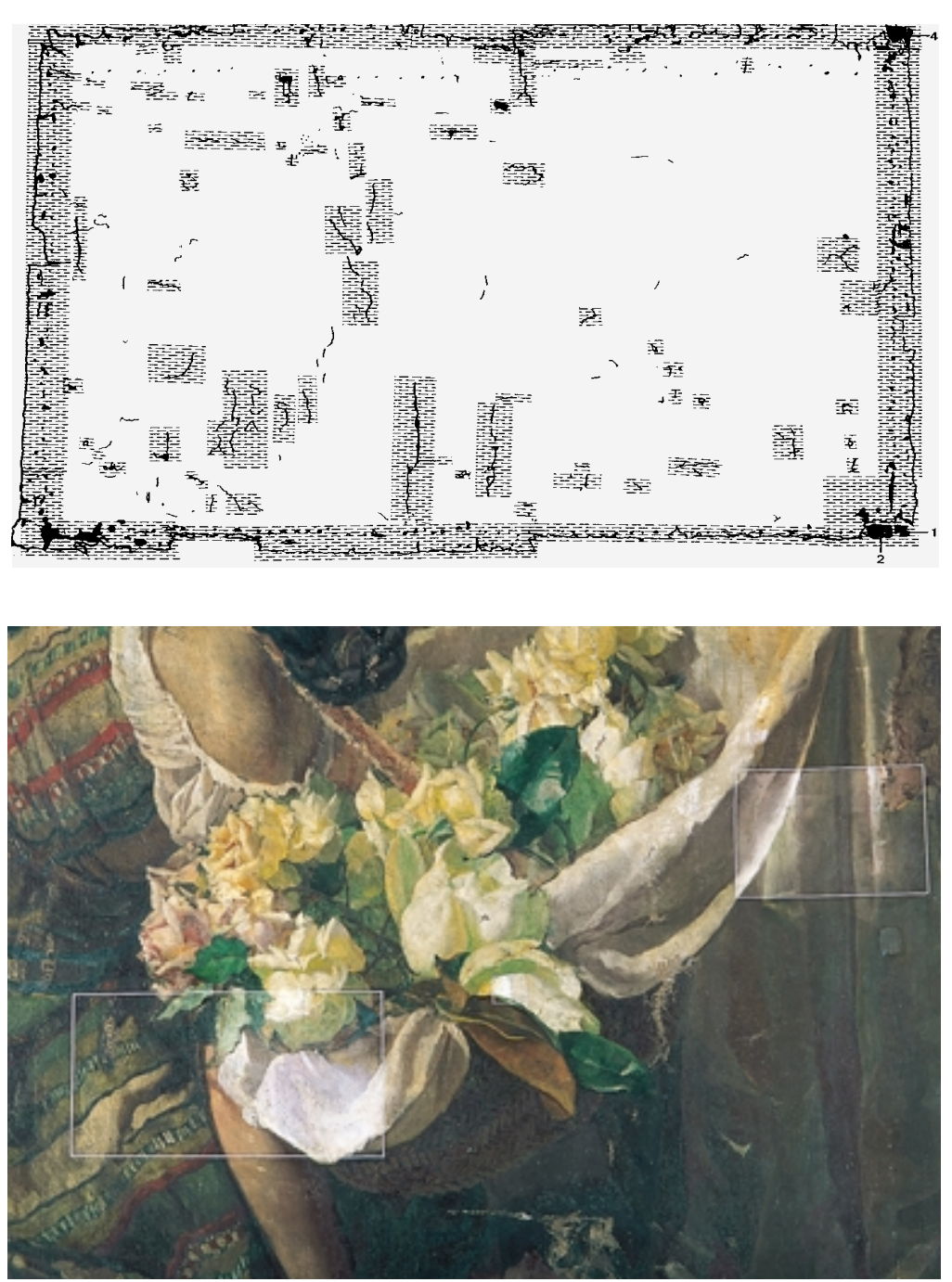

Catas de limpieza de la película pictórica.

La primera de ellas fue la prueba de limpieza del soporte pictórico para eliminar la suciedad sin dañar la fibra de la tela original, muy debilitada por el grado de deterioro que sufría la misma. Los resultados más satisfactorios fueron los obtenidos mediante el cepillado en sentido circular, pues permitía eliminar no sólo la suciedad superficial, sino la incrustada entre los hilos de la tela.

La segunda de ellas fue la prueba de encogimiento, que dio negativa, al permanecer intactos los bordes y dimensiones totales de la pieza, tras ser sometida a un proceso de impregnación y secado a temperatura ambiente, sin sujeción previa de la tela.

\section{PREPARACIÓN, PELÍCULA PICTÓRICA Y CAPA DE PROTECCIÓN}

Para poder enrollar el cuadro en el rulo para su traslado, la película pictórica se protegió con papel japonés y coleta. Esta protección impedía determinar con exactitud el estado de conservación de la misma, así como de la preparación y estrato superficial.

Mediante un examen visual se pudieron detectar los refuerzos de los rotos del lienzo con papel japonés y la cinta de papel de embalar en el borde superior, posiblemente aprovechada de otro embalaje al presentar el timbre y sello de correos. Igualmente se pudieron comprobar las medidas exactas del cuadro: $305 \mathrm{~cm} \times 450 \mathrm{~cm}$.

Los datos obtenidos sobre la composición de la preparación y el color de las muestras analizadas, no se podían considerar determinantes para valorar el estado de conservación. La historia material de la obra nos daba una idea de las alteraciones que había sufrido el lienzo $y$, por consiguiente, la influencia de estos daños en el estado de conservación de la película de color.

\section{Propuesta de Tratamiento}

Según los resultados de los datos obtenidos hasta el momento, se propuso una restauración completa de la obra, teniendo en cuenta que por el desconocimiento del estado de conservación real de la película pictórica antes de comenzar la intervención, sería necesaria la realización de nuevos análisis una vez iniciado el proceso de restauración, así como durante el transcurso del mismo. Éstos análisis consistirían en una analítica completa de las capas de preparación y color, mediante la extracción de muestras de los distintos colores utilizados en la obra y en distintas zonas (con o sin repinte), la identificación de los adhesivos, de los barnices y de las alteraciones microbiológicas y, por último, el estudio de la obra mediante radiaciones no visibles (Infrarrojos, Ultravioletas y rayos $\mathrm{X}$ ).

\section{PROCESO DE RESTAURACIÓN}

El proceso de restauración se inició en diciembre de 1997, siguiendo las pautas del informe preliminar realizado en julio del mismo año.

\section{Soporte pictórico}

\section{Estudios previos.}

Los primeros estudios se llevaron a cabo sobre las dos piezas de tela original del ángulo inferior derecho (por el reverso), donde se realizaron las pruebas de adherencia de los parches de seda, así como el grado de concentración del consolidante para reforzar el soporte pictórico. 
Al iniciar el tratamiento del soporte pictórico, aparecieron otras dos piezas de tela desprendidas en el borde superior derecho del cuadro, al eliminar el papel de embalar y la gasa que lo reforzaba.

Los estudios sobre dichas piezas de tela, numeradas como 3 y 4, determinaron la construcción interna del tejido: Louisine, lo que demostró que no se trataba de injertos o añadidos sino que ambas piezas pertenecían al soporte original.

Al igual que en las piezas de tela $n^{\circ} 1$ y $n^{\circ} 2$, se realizaron las pruebas de adherencia de los parches de seda, para reforzar los rotos y desgarros del soporte original, y la prueba de encogimiento del mismo, que también fue negativa. Esto nos garantizó el empleo de adhesivos y protectivos en medio acuoso, sin riesgo para la obra.

\section{Estudios fisicos.}

Mediante un examen visual minucioso con lupa binocular y cuentahilos, se identificó la fibra de algodón en los diferentes parches que presentaba la obra y el estudio de la construcción interna del tejido permitió agruparlos en tres bloques diferentes, según la densidad de los hilos por $\mathrm{cm}^{2}$.

En la banda de papel de embalar y de gasa, de unos 6 $\mathrm{cm}$ de ancho, dispuestas en el borde superior del lienzo, para reforzarlo tanto por el anverso como por el reverso, se observaron perforaciones de ataque biológico.

El papel de periódico estaba adherido a un parche de tela que ocultaba uno de los innumerables rotos del soporte pictórico.

La eliminación de la suciedad acumulada, mediante procedimiento mecánico de cepillado en sentido circular, permitió observar el comportamiento de los restos de manchas de humedad y ver hasta donde dañaba al soporte pictórico. Dichas manchas eran muy superficiales y sólo en algunos casos, presentaba decoloración la tela.

\section{Análisis biológico.}

Las numerosas manchas repartidas por toda la tela original (sobre todo en el ángulo inferior derecho), demostraban que el soporte pictórico había estado sometido a un elevado porcentaje de humedad, al haber permanecido en contacto directo con el muro o pared.

Para conocer la presencia o no de posibles microorganismos causantes del deterioro, se tomaron un total de II muestras en 6 zonas diferentes del lienzo 9

Los cultivos de dichas muestras dieron como resultado la existencia de hongos llamados Hiphomycetes y entre ellos: Alternaría, Cladosporium, Aspergillus y Penicillium. Estos microorganismos causan daños químicos al soporte por las sustancias que excretan al exterior, y daños mecánicos por la penetración de las hifas en el substrato, que pueden llegar a producir disgregación del material y hasta el levantamiento de la película pictórica.

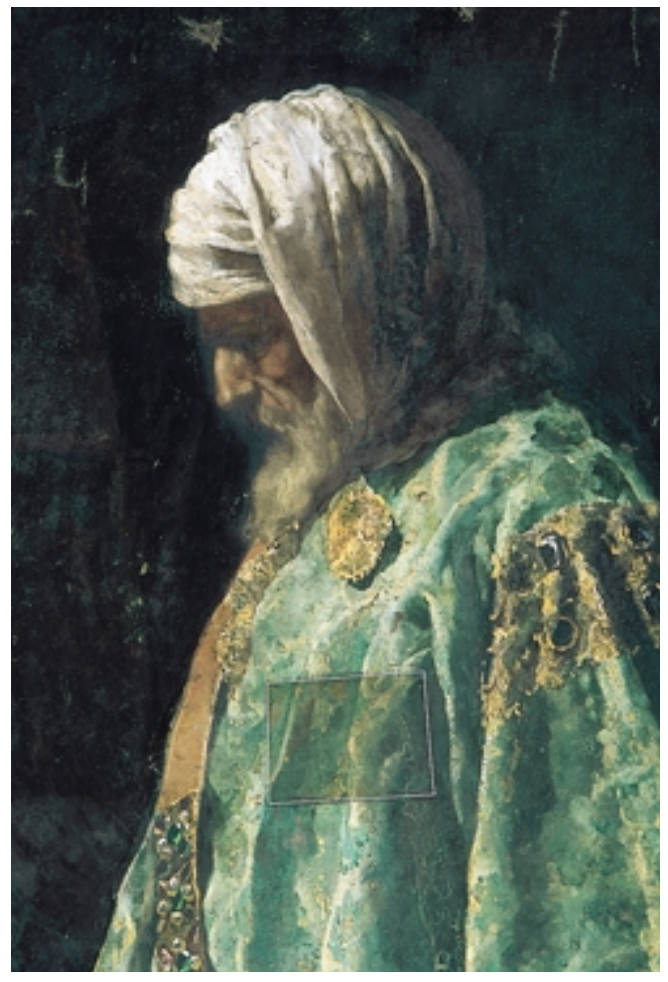

$\frac{⿱ 亠 乂}{\infty}$

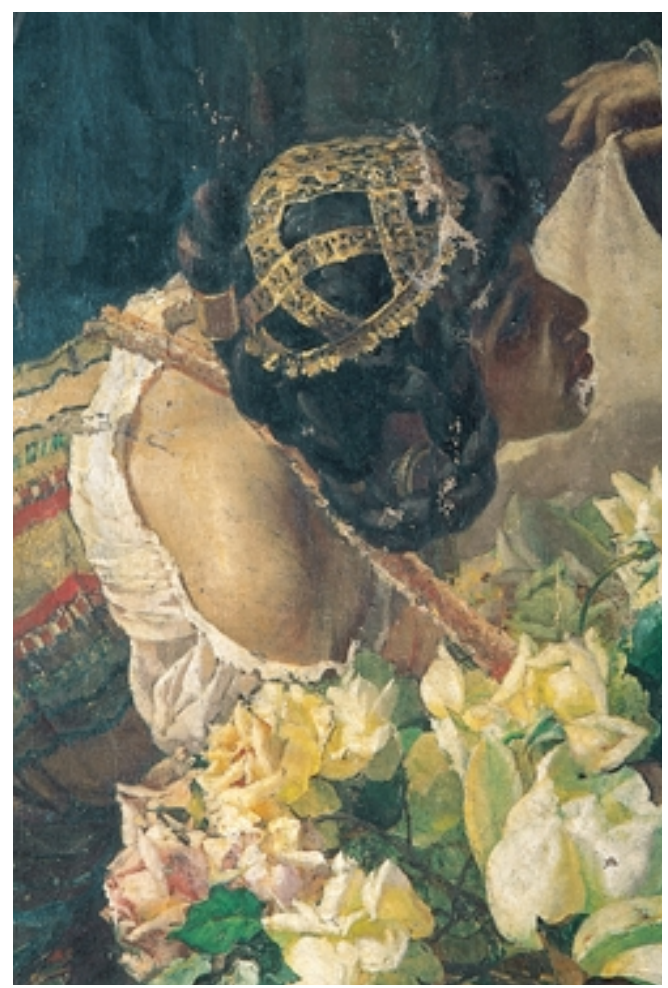
fase de limpieza de la película pictórica.

Detalle de la sierva con las flores antes de eliminar el barniz superficial.
Igualmente, en el análisis del serrín adherido en la zona inferior del cuadro, se detectó la existencia de excrementos de insectos xilófagos, en concreto de anóbidos. En el borde superior del lienzo se observaron orificios y perforaciones redondas causadas por estos insectos, que probablemente anidaron en el listón de madera que en su día tuvo el cuadro clavado en el borde superior, para poder anclarlo al muro. 
$\frac{\pi}{0}$
$\vdots$
$\Sigma$
$\Sigma$

Fase de estucado. croorganismos eran las que estaban en contacto directo con la pared, favorecido dicho ataque por las infiltraciones, el ascenso de la humedad, la escasa ventilación y la temperatura $\left(20-30^{\circ} \mathrm{C}\right)$, por lo que no se aconsejó el llevar a cabo ningún tratamiento específico contra los microorganismos, sólo mantener un control de las condiciones ambientales mediante la disminución de la humedad relativa y el aumento de la aireación.

En cuanto al ataque de insectos xilófagos, ya sin actividad, no se observaron daños suficientemente importantes como para tener que exponer la obra a un tratamiento de desinsectación.

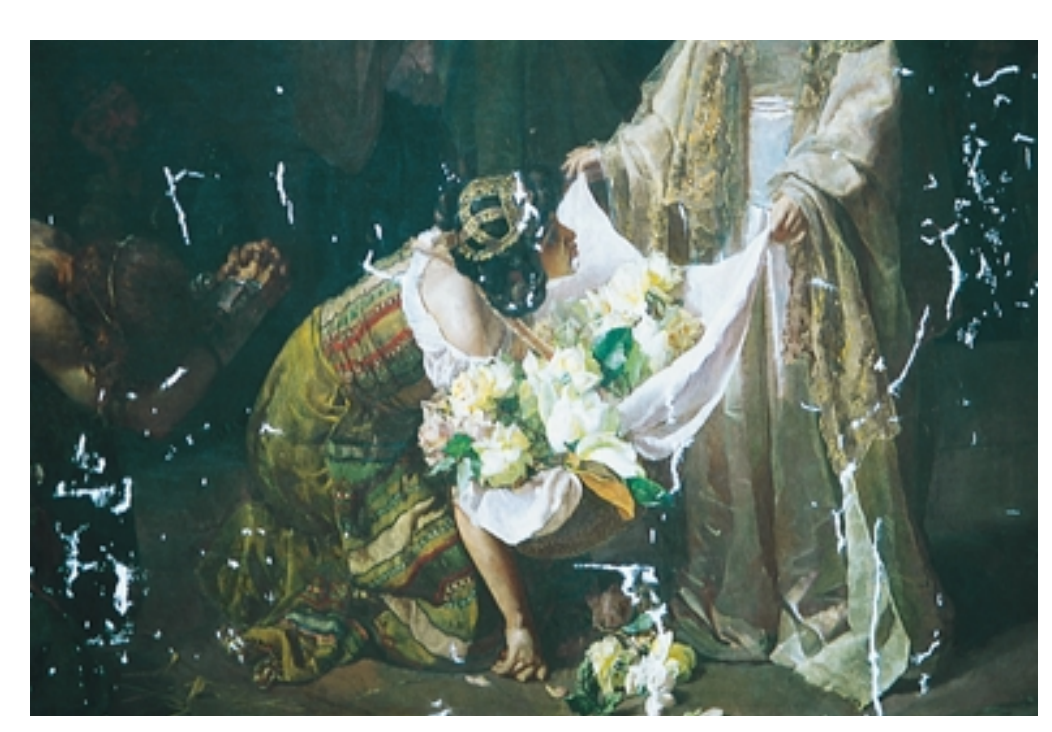

Las zonas de la obra más expuestas al ataque de mi-

Proceso de restauración.

La limpieza del soporte pictórico se llevó a cabo de forma mecánica, en seco, quitando los depósitos superficiales con brocha, sin presionar y en sentido circular para no dañar la fibra.

Finalizada esta primera limpieza, se eliminaron todos los elementos extraños al soporte original (restos metálicos, parches de tela y las bandas de gasa y papel del borde superior) y se pudo apreciar su estado de conservación, pues presentaba infinidad de rotos, agujeros, desgarros y bordes irregulares.

Ante la imposibilidad de poder realizar una toma fotográfica general del estado de conservación del soporte pictórico, dadas las dimensiones de la obra y la disposición del propio taller, se dispuso una trama sobre la tela, con hilos blancos de algodón, formando cuadrantes de $|\times|$ m. Esta trama permitió reproducir a escala los diferentes daños del soporte pictórico.

Las deformaciones de la tela se corrigieron mediante la aplicación de humedad y peso, y posteriormente se consolidó con coleta diluida en agua. La observación detallada de los diferentes rotos y desgarros de la tela y su grado de deterioro, determinó la ubicación de los parches y de las bandas de todo el perímetro exterior, que se aplicaron mediante brocha y coleta, a tenor de los resultados obtenidos en las piezas de tela $n^{\circ} 1,2,3$ y 4 , piezas que se ubicaron en su lugar original mediante parches de seda natural.

Finalizados los trabajos sobre el soporte pictórico, se enrolló el cuadro en el rulo y se depositó el telar 10 sobre la plataforma de trabajo, para poder proceder al reentelado a la gacha, según el método tradicional: impregnadas ambas superficies con gacha (tela nueva y tela original), se fue desenrollando el lienzo sobre la tela del telar, $y$, desde el puente de trabajo, se planchó el cuadro cuatro veces, aplicando humedad en los tres últimos y dejando intervalos de descanso y aireación entre ellos.

Una vez reentelado el cuadro y antes de montarlo en su nuevo bastidor, en el mismo telar se eliminaron los papeles de protección de la película pictórica con humedad y se pudieron apreciar las medidas reales de la pintura $(301 \times 446 \mathrm{~cm})$. Dicho bastidor, se realizó en madera curada de pino, con listones de corte longitudinal y sección rectangular, unidos entre sí con ensambles de doble lengüeta (bastidor), de caja y espiga (entre bastidor y travesaño) y a media madera (entre travesaños), y con sistema de expansión mediante cuñas, dobles en los ángulos del bastidor y simples entre bastidor y travesaños.

El montaje del lienzo en el bastidor se hizo con grapas, aprovechando la propia tensión de la tela en el telar, dejando caer el telar sobre el bastidor y grapando. Entre las grapas y la tela se colocaron unas cintas de unos $2 \mathrm{~mm}$ de grosor, a modo de almohadilla, para proteger la tela original en el caso de tener que desmontar el lienzo del bastidor para su traslado, al tratarse de un lienzo de gran formato.

\section{PELÍCULA PICTÓRICA, PREPARACIÓN Y ESTRA- TO SUPERFICIAL}

Eliminados los papeles de protección se pudieron observar los daños reales de la película pictórica.

El primer estudio sobre ella consistió en un barrido fotográfico completo. Para ello, se distribuyó el cuadro en nueve cuadrantes, realizando tomas fotográficas de los mismos con luz normal, luz rasante y luz UV. 'I. Estos estudios mediante radiaciones no visibles, corroboraron los datos obtenidos mediante la inspección ocular, en cuanto a los levantamientos y cuarteados prematuros en las zonas de empaste (luz rasante); y en cuanto a la acumulación de barniz en algunas zonas de la película pictórica (luz UV).

\section{Estado de conservación.}

El estado de conservación del soporte pictórico, la preparación y el estrato superficial, repercutía directamente en la película pictórica y determinaba el grado de deterioro de la misma. Así, a través de la capa pictórica se podían observar las faltas, agujeros y rotos del soporte pictórico, las lagunas de la capa pictórica y las lagunas de preparación, que en la mayoría de los casos coincidían con las faltas del soporte pictórico (rotos, agujeros y desgarros). 
Los agujeros en los bordes de la tela eran una señal evidente de haber tenido en su día un bastidor, al igual que lo muestra la preparación en los bordes superior y lateral izquierdo, marcados por el alabeo propio del bastidor original, dadas las dimensiones del cuadro.

El cuarteado prematuro de la pintura coincidía con las zonas de color oscuro y de mayor empaste, localizadas principalmente en la figura del padre, en el fondo a la izquierda de la santa y en el ropaje de la sierva. A pesar de la acumulación de barnices, también se pudo apreciar las zonas decoloradas por la alteración microbiológica, sobre todo en el ángulo superior izquierdo, fondo central (sobre la santa) y en la zona inferior, a los pies del padre.

\section{Análisis químico.}

Se tomaron un total de siete muestras que se enumeraron de forma correlativa a las recogidas en el estudio analítico previo realizado en junio de 1997.12

Las muestras tomadas fueron las siguientes:

\begin{tabular}{ll}
\hline Vestimenta del padre & verde \\
\hline Manto de la santa & ocre claro \\
\hline Rosas del suelo & amarillo limón \\
\hline Vestido sierva & rojo \\
\hline Vestido sierva & azul \\
\hline Espalda sierva & carnación \\
\hline Fondo & tierra oscura \\
\hline
\end{tabular}

Los análisis efectuados sobre dichas muestras fueron el examen con lupa binocular, observación al microscopio óptico con luz reflejada de la sección transversal (estratigrafía), el estudio al microscopio electrónico de barrido y microanálisis (EDAD) de la sección transversal y los ensayos microquímicos con diversos reactivos.

Los resultados obtenidos fueron los siguientes:

- Las carnaciones estaban resueltas con blanco de plomo, laca roja y bermellón.

- Los rojos resultaban de la mezcla de bermellón y tierra roja con blanco de plomo.

- Los azules estaban compuestos por blanco de plomo, ultramar y pequeñas cantidades de tierras y verde óxido de cromo.

- Los verdes eran a base de la mezcla de blanco de plomo, verde de óxido de cromo y pequeñas cantidades de tierra roja y bermellón.

- Los ocres estaban constituidos por ocre, blanco de plomo y trazas de tierras, carbón y ultramar.

- En los amarillos no se pudo determinar el pigmento responsable de la coloración, por lo que se supone que se trata de un pigmento orgánico ${ }^{13}$, no identificable con las técnicas analíticas empleadas.

En las estratigrafías estudiadas el número de capas oscila entre dos y cuatro, y hasta seis. Las más simples

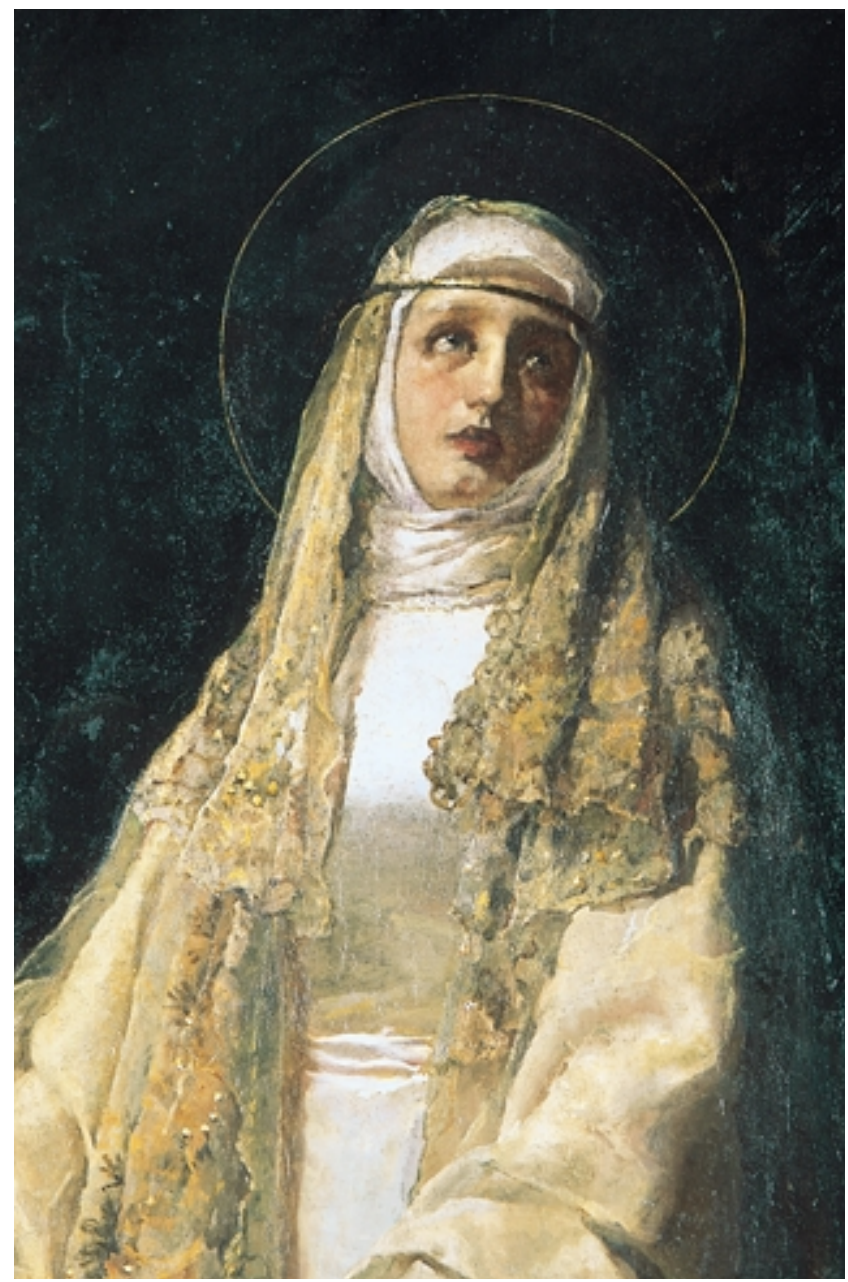

$\frac{\nwarrow}{\Sigma}$

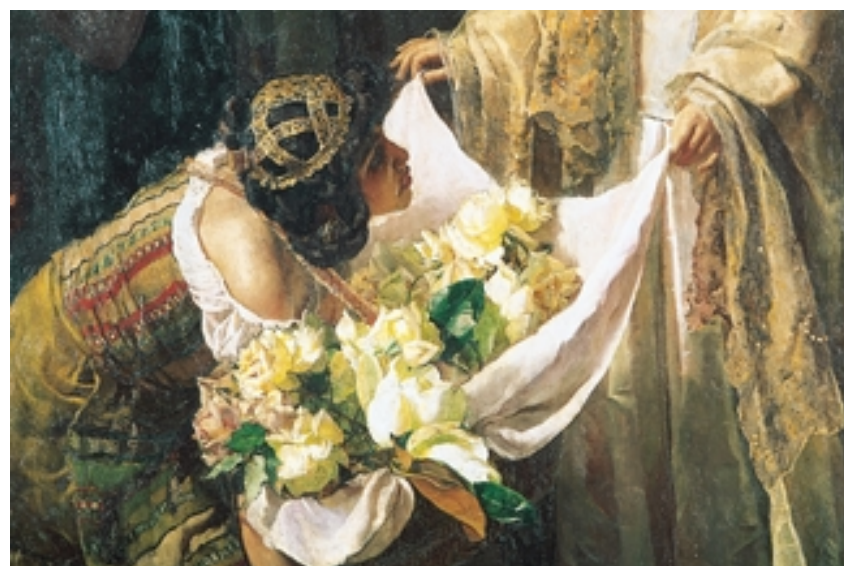

Personaje de la santa finalizado el proceso de restauración

están compuestas por dos capas, como es el caso de la muestra de color azul del vestido de la sierva, y en la muestra del fondo de color marrón.

Motivo central del cuadro finalizada la restauración.
En la muestra que corresponde al color del fondo, la primera capa es de imprimación, compuesta por blanco fijo y blanco de plomo. Esta capa se mantiene en las demás estratigrafías estudiadas, oscilando su espesor entre 15 y 125 micras. La segunda y última capa de esta muestra corresponde al color marrón del fondo, compuesto por blanco de plomo, tierras pardas y carbón. Esta capa, cuyo espesor oscila entre 5 y 75 
micras, se encuentra en todas las estratigrafías estudiadas, y de su disposición podríamos sacar las siguientes conclusiones:

I Si observamos la localización de la extracción de las muestras analizadas, podemos ver que la mayoría de las muestras se extrajeron de faltas de la película pictórica muy cercanas a los bordes que delimitan volúmenes o espacios diferentes (fondo-figura, figura-ropaje). Se podría pensar que el autor reservaba el espacio de los personajes, tapando parte de las zonas ya pintadas con el color del fondo, al superponer capas de color para encajar y componer la figura y los pliegues del ropaje.

$2^{\circ}$ En la muestra correspondiente a la carnación, se compagina esta capa de color de la muestra del fondo (color marrón), con otra de color negro, compuesta por carbón y quizás un poco de blanco de plomo, de un espesor muy reducido, y que podría corresponder al "carboncillo" utilizado para el dibujo. Al encontrarse éste entre dos capas de color, podría haber sido arrastrado por la pincelada. En otros casos, como en la muestra del color amarillo limón, no existe la capa de color marrón, pero sí la capa de color negro, que podría corresponder al dibujo previo.

$3^{\circ}$ En todas las muestras estudiadas no se observa ninguna capa que corresponda al substrato superficial o barniz.

Proceso de restauración.

El test de solubilidad mediante microcatas realizadas en los diferentes colores de la película pictórica, demostró que el estrato superficial oscurecido y opaco, se podía eliminar con la mezcla de dicloroetano y me- tanol (50:50). La evaporación rápida de la mezcla anterior, pasmaba la superficie, dándole un aspecto blanquecino, que sólo se regeneraría con tolueno y dimetil (75:25), recuperando la pintura su color original.

Para garantizar la efectividad de la mezcla de disolventes empleados para eliminar el barniz y conocer la naturaleza de éste, se recogieron muestras mediante hisopos impregnados en dicha mezcla. Se tomaron dos muestras diferentes: Una en la manga izquierda de la santa, donde además de barniz había bastante suciedad impregnada; y la otra en el paño de las flores. Estos análisis químicos ${ }^{14}$ dieron como resultado la presencia de una resina natural, posiblemente Gomalaca ${ }^{15}$ y, en ambas muestras, no se detectó ningún tipo de pigmento.

Durante la limpieza de la película pictórica se examinó el cuadro con luz UV para comprobar el grado de limpieza y los resultados obtenidos.

Eliminado el estrato superficial se injertaron las faltas de soporte pictórico con gasa, adherida mediante "gacha" diluida, y antes de iniciar la fase de estucado de lagunas con sulfato cálcico y cola animal.

Las zonas estucadas se reintegraron con acuarela, y después con pigmentos al barniz (Maimeri) mediante puntos y rayas, en algunos casos, y veladuras de color en otros. También se reintegraron las zonas más decoloradas que presentaba la película pictórica y confundían la lectura cromática del cuadro.

Para proteger estas reintegraciones y la totalidad de la capa de color, se aplicó un barniz pulverizado, dando por finalizada la restauración de la obra en marzo de 199916.

Ficha técnica

Dirección del trabajo:

Lorenzo Pérez del Campo,

Jefe del Centro de Intervención del IAPH.

Proceso de restauración, informe técnico y documentación gráfica:

Ma del Mar González González, restauradora.

Departamento de Tratamiento. Centro de Intervención del IAPH.

Estudio histórico-artístico:

Gabriel Ferreras Romero, historiador.

Departamento de Investigación. Centro de Intervención del IAPH.
Documentación analítica:

Lourdes Martín García, química:

Marta Sameño Puerto, bióloga;

Francisco Gutiérrez Montero, químico.

Departamento de Análisis. Centro de Intervención del IAPH.

Documentación fotográfica:

Eugenio Fernández Ruiz, fotógrafo.

Departamento de Análisis. Centro de Intervención del $\mathrm{IAPH}$. 
I. La obra fundamental para el conocimiento científico de la pintura malagueña del siglo XIX se debe a la profesora de la Universidad de Málaga Teresa Sauret "El siglo XIX en la pintura malagueña del s.XIX" (1987). Un resumen general de la época, por la misma profesora, está disponible en "Panorámica de la pintura malagueña en el nacimiento de un genio" en Una Sociedad a Fines del Sig/o XIX: Málaga. págs. 55/92. (198I). Sobre José Nogales el estudio más completo es el del profesor José Miguel Morales Folguera, de la Universidad de Málaga, titulado "José Nogales Sevilla" (1973).

2. Instituto Andaluz del Patrimonio Histórico. Centro de Intervención. Expediente 1/97. En este expediente constan, entre otros documentos, todos los informes técnicos a que se hace referencia en este trabajo.

3. Informe de Valoración a petición del Servicio de Instituciones del Patrimonio Histórico de la Dirección General de Bienes Culturales, correspondiente a la obra: "El Milagro de Santa Casilda", realizado por Elisa Pinilla Pinilla. Junio de 1994.

4. Informe sobre la protección, descolgamiento de un muro y enrollado en el rulo del cuadro de J. Nogales "Milagro de Santa Casilda", realizado por Clara González-Fanjul, en octubre de 1996.

5. Informe del "Estudio analítico previo" realizado en junio de 1997 por Lourdes Martín García. Departamento de Análisis.

6. El blanco de plomo es el blanco utilizado por excelencia en la pintura al óleo, al ser muy opaco y no oscurecer al mezclarse con aceites $u$ otros colores permanentes, entre otras de las muchas ventajas recogidas por Ralph Mayer en su manual sobre "Materiales y técnicas del Arte" (1988).

7. La escasa presencia de este pigmento impide determinar con exactitud su composición, pero la base podría ser cobalto, pigmento comercializado en el primer tercio del siglo XIX.

8. Denominación basada en los estudios realizados por el "Centre International D'étude des textiles anciens". C.I.E.T.A. Tracés Techniques. Lyon. 1979.
9. Informe del "Estudio biológico y microbiológico" realizado en marzo de 1998 por Marta Sameño Puerto. Departamento de Análisis.

10. Antes de montar la plataforma de trabajo en el taller, se montó en el telar metálico $\left(5^{\prime} 06 \times 3^{\prime} 39 \mathrm{~m}\right)$ la tela de lino (5'62 × 3'95 m), pues al tratarse de un lienzo de gran formato y estar paralelamente realizándose restauraciones de otros cuadros, fue necesario contar con una adecuada distribución del espacio en el taller, y el preparar y disponer el material fungible necesario para una correcta manipulación de la obra en los diferentes procesos de restauración. Estos datos están recogidos en el Informe Preliminar del Estado de Conservación y Propuesta de Tratamiento realizado por $M^{a}$ del Mar González González en Julio de 1997. Departamento de Tratamiento.

II. Con la iluminación UV se detectó una fluorescencia diferente en las hojas de las flores de color amarillo o con base de color amarillo o verde limón. El análisis químico de este color, comprobó que se trataba de un pigmento orgánico, de ahí su comportamiento diferente ante la iluminación UV.

12. Informe de los "Estudios analíticos", realizados en febrero de 1999 por Lourdes Martín García. Departamento de Análisis.

13. Montagna, Giovanni. "I pigmenti. Prontuario per l'arte e il restauro". Nardini Editore. Firenze. 1993.

14. Informe de los "Análisis químicos" mediante Espectrometría Infrarroja por Transformada de Fourier, realizados por Francisco Gutiérrez Montero en septiembre de 1998. Departamento de Análisis.

15. Doerner, Max. "Los materiales de la pintura y su empleo en el arte". Ed.: Reverté S.A. Barcelona. 1975.

16. Finalizada la restauración integral del cuadro, le fue colocado una moldura de $4 \mathrm{~cm}$ de ancho y $6 \mathrm{~cm}$ de profundidad, realizada por Rafael López Gómez (dorador). 